\title{
Rare Earth Oxide-Treated Fullerene and Titania Composites with Enhanced Photocatalytic Activity for the Degradation of Methylene Blue
}

\author{
MENG Zada, ZHU Lei, CHOI Jong-geun, PARK Chong-yeon, OH Won-chun* \\ Department of Advanced Materials Science \& Engineering, Hanseo University, Seosan, Chungnam 356-706, Korea
}

\begin{abstract}
Rare earth oxide-treated fullerene and titania composites (Y-fullerene/ $\mathrm{TiO}_{2}$ ) were prepared by the sol-gel method. The products had interesting surface compositions. X-ray diffraction patterns of the composites showed that the Y-fullerene/ $/ \mathrm{TiO}_{2}$ composites contained a single and clear anatase phase. The surface properties were observed by scanning electron microscopy, which gave a characterization of the texture on the Y-fullerene/ $/ \mathrm{TiO}_{2}$ composites and showed a homogenous distribution of titanium particles. The energy-dispersive X-ray spectra showed the presence of $\mathrm{C}$ and $\mathrm{Ti}$ with strong $\mathrm{Y}$ peaks. The composite obtained was also characterized with transmission electron microscopy and UV-Vis spectroscopy. The photocatalytic results showed that the Y-fullerene/ $\mathrm{TiO}_{2}$ composites had excellent activity for the degradation of methylene blue under visible light irradiation. This was attributed to both the effects on the photocatalysis of the supported $\mathrm{TiO}_{2}$ by charge transfer by the fullerene, and the introduction of yttrium to enhance photo-generated electron transfer.
\end{abstract}

Key words: fullerene; yttrium; titania; visible light; methylene blue

CLC number: O643 Document code: A

Received 17 April 2011. Accepted 28 May 2011.

*Corresponding author.Tel: +82-41-660-1337; Fax: +82-41-688-3352; E-mail: wc_oh@hanseo.ac.kr

English edition available online at Elsevier ScienceDirect (http://www.sciencedirect.com/science/journal/18722067).

$\mathrm{TiO}_{2}$-induced photocatalysis is an established advanced oxidation process for the treatment of contaminated aqueous and gaseous streams. However, poor adsorption capacity, rapid formation of aggregates in a suspension, and recycling difficulties have restricted the utilization of pure $\mathrm{TiO}_{2}[1-4]$. Furthermore, the recombination of photo-generated electron-hole pairs $\left(\mathrm{e}^{-}-\mathrm{h}^{+}\right)$also results in a low photo quantum efficiency for $\mathrm{TiO}_{2}$ [5,6]. The effective separation of $\mathrm{e}^{-}-\mathrm{h}^{+}$pairs, therefore, is one of the most important problems to overcome in the applications of a $\mathrm{TiO}_{2}$ photocatalyst.

$\mathrm{TiO}_{2}$ has been intensively investigated for the complete degradation of recalcitrant organic pollutants because it is easily available, nontoxic, cheap, and chemically stable. However, $\mathrm{TiO}_{2}$ has some shortcomings in its application in practice: the difficult separation of $\mathrm{TiO}_{2}$ from the aqueous phase, relatively low quantum yield due to the rapid recombination of charge carriers, and activity only in the UV range. To induce visible light activity in $\mathrm{TiO}_{2}$, the band gap must be shifted to lower values. Visible light activity can be induced by doping $\mathrm{TiO}_{2}$ with various metal atoms such as $\mathrm{Pt}, \mathrm{Ag}, \mathrm{W}, \mathrm{Ru}$, and $\mathrm{Cu}$.

Nanocarbon materials such as fullerenes and carbon nanotubes have been intensively investigated due to their unique structure, electric and mechanical properties [7-9].
Metal oxide-based inorganic surfaces formed by covalent/noncovalent bonding onto nanocarbon materials have been attractive for optical, electronic, photovoltaic, artificial photosynthesis, and solar cell applications [10-13]. Fullerenes and their derivatives are promising candidates for these applications because of their rich $\pi$-electron systems and the resulting electron-acceptor properties [14-16].

Although both theoretical and experimental studies suggested that significant electron transfer from metal atom to the carbon cage occurs when a metal atom is encapsulated in a fullerene cage, metallofullerenes still have good electron accepting abilities [17,18]. Electrochemical studies on metallofullerenes showed that up to six electrons can be added to them $[19,20]$. So far, only the electrochemical properties of the lanthanide metallofullerenes $\mathrm{M} @ \mathrm{C}_{82}$ in Group A have been reported. Their similar redox behavior suggested that the entrapped metal atoms adopted the same trivalent cation state.

Fullerenes have attracted extensive attention for their various interesting properties due to their delocalized conjugated electronic structures and electron accepting ability. A remarkable property of fullerene in electron transfer processes is that it can efficiently cause a rapid photo-induced charge separation, which results in a relatively slow charge recombination [21]. Thus, the 
combination of photocatalysts and fullerene may achieve enhanced charge separation by photo-induced electron transfer.

Recently, photocatalysts prepared with the doping of rare earth oxides to increase the photocatalytic activity of anatase $\mathrm{TiO}_{2}$ have attracted much attention [22-24]. It is well known that the surface composition and structure of a photocatalyst can greatly influence its activity. Some important results have been achieved by studies on rare earth oxide-doped $\mathrm{TiO}_{2}$ composites. For example, Zhang et al. [25] and Saif et al. [26] reported that $\mathrm{TiO}_{2}$ nanocomposites doped with trivalent lanthanide ions (e.g. $\mathrm{Tb}^{3+}, \mathrm{Eu}^{3+}$, and $\mathrm{Sm}^{3+}$ ) exhibited remarkably enhanced photocatalytic activity for textile dye degradation when compared to pure $\mathrm{TiO}_{2}$. Yan et al. [24] reported that rare earth-doped $\mathrm{TiO}_{2}$ had its photocatalytic activity increased after adding the rare earth elements, and the shift of the band gap energy was a red shift in the order of $\mathrm{La}^{3+}<\mathrm{Pr}^{3+}<$ $\mathrm{Nd}^{3+}<\mathrm{Y}^{3+}$-doped $\mathrm{TiO}_{2}$, as observed in the solid state UV-Vis spectra. On the basis of these studies, we have prepared some novel photocatalytic materials using $\mathrm{TiO}_{2}$ loaded on the surface of fullerene and the further incorporation of $\mathrm{Y}^{3+}$ ions into the $\mathrm{TiO}_{2}$ supported on the fullerene surface.

The surface sol-gel process was used to prepare the Y-fullerene/ $/ \mathrm{TiO}_{2}$ compounds. In this technique, metal oxides were chemisorbed on a solid substrate modified with surface hydroxyl groups. To explore the synergism induced after $\mathrm{TiO}_{2}$ and $\mathrm{Y}_{2} \mathrm{O}_{3}$ nanoparticles were adsorbed on the fullerenes surface, the photocatalysts prepared have been examined by X-ray diffraction (XRD), $\mathrm{N}_{2}$ adsorptiondesorption, scanning electron microscopy (SEM), energydispersive X-ray spectroscopy (EDX), transmission electron microscopy (TEM), and UV-Vis spectroscopy. The catalytic performances of these new materials were tested under visible light illumination for the photocatalytic decolorization of methylene blue (MB). MB is a watersoluble azo dye produced in the textile, printing, paper manufacturing and pulp processing, and pharmaceutical industries. It is a major water pollutant in these industries and its release into the environment is a problem. It was selected as the test reactant because under anaerobic conditions it has the potential to produce more hazardous aromatic amines. Its decolorization was studied for the effect of the yttrium ion content.

\section{Experimental}

\subsection{Preparation of $\mathrm{Y}$-fullerene/ $\mathrm{TiO}_{2}$ composites}

For the oxidation of the fullerene $\left(\mathrm{C}_{60}, 99.9 \%\right.$ purity, Tokyo Kasei Kogyo Co. Ltd., Japan) surface, $m$-chloroperbenzoic acid (MCPBA, ca. $1 \mathrm{~g}$ ) was suspended in $50 \mathrm{ml}$ benzene, followed by the addition of $\mathrm{C}_{60}$ (ca. 100 $\mathrm{mg}$ ). The mixture was refluxed in an air atmosphere and stirred for $6 \mathrm{~h}$. The solvent was dried at the boiling point of benzene $(353.13 \mathrm{~K})$. After drying, the dark brown precipitates were washed with ethyl alcohol and dried at 323 K. For yttrium decoration, yttrium nitrate $\left(\mathrm{Y}\left(\mathrm{NO}_{3}\right)_{3}\right.$, Daejung Chemicals \& Metals Co., Ltd, Korea) was used as the yttrium source. The concentration of the yttrium nitrate solution used was $0.013,0.026$, and $0.039 \mathrm{~mol} / \mathrm{L}$, respectively. The mixture of $\mathrm{C}_{60}$ and yttrium nitrate solution was refluxed in an air atmosphere and stirred at $343 \mathrm{~K}$ for 6 $\mathrm{h}$ using a magnetic stirrer in a vial. After heat treatment at $923 \mathrm{~K}$ for $1 \mathrm{~h}$, the $\mathrm{Y}$-fullerene composites were obtained.

The Y-fullerene composites were put into a solution of titanium $n$-butoxide (TNB, $\mathrm{C}_{16} \mathrm{H}_{36} \mathrm{O}_{4} \mathrm{Ti}$, Acros Organics, USA) and benzene with a volume ratio of $3: 47$. The solution was homogenized under reflux at $343 \mathrm{~K}$ for $5 \mathrm{~h}$ while being stirred in a vial. After stirring, the solution was transformed into Y-fullerene/ $/ \mathrm{TiO}_{2}$ gels, and these gels were heat treated at $873 \mathrm{~K}$ to give the $\mathrm{Y}$-fullerene $/ \mathrm{TiO}_{2}$ composites. The $\mathrm{Y}$-fullerene $/ \mathrm{TiO}_{2}$ composites prepared with $0.013,0.026$, and $0.039 \mathrm{~mol} / \mathrm{L}$ yttrium nitrate solution are denoted as YCT1, YCT2, and YCT3.

\subsection{Characterization of the $\mathrm{Y}$-fullerene/ $\mathrm{TiO}_{2}$ composites}

XRD was used for crystal phase identification and estimation of the anatase-to-rutile ratio. XRD patterns were obtained at room temperature with a diffractometer (Shimadzu XD-D1, Japan) using $\mathrm{Cu} K_{\alpha}$ radiation. SEM was used to observe the surface state and porous structure of the $\mathrm{Y}$-fullerene/ $/ \mathrm{TiO}_{2}$ composites using a scanning electron microscope (JOEL, JSM-5200, Japan). EDX spectroscopy was used for the elemental analysis of the $\mathrm{Y}$-fullerene/ $/ \mathrm{TiO}_{2}$ composites. TEM (JEOL, JEM-2010, Japan) at an acceleration voltage of $200 \mathrm{kV}$ was used to observe the surface state and structure of the photocatalyst composites. TEM was also used to examine the size and distribution of the titanium and iron particles deposited on the fullerene surface of the various samples. The TEM specimens were prepared by placing a few drops of the sample solution on a carbon grid. UV-Vis diffused reflectance spectra were obtained using an UV-Vis spectrophotometer (Neosys-2000) by using $\mathrm{BaSO}_{4}$ as a reference, and the data were converted from reflection to absorbance by the Kubelka-Munk method.

\subsection{Photocatalytic tests}

The photocatalytic activities were evaluated by MB 
(analytical grade, Duksan Pure Chemical Co., Korea) degradation in aqueous media under visible light irradiation. For the visible light irradiation, the reaction beaker was placed axially and held in a visible lamp ( $8 \mathrm{~W}$, halogen lamp, KLD-08L/P/N, Korea) box. The luminous efficacy of the lamp was $80 \mathrm{~lm} / \mathrm{W}$ and the wavelength was 400-790 $\mathrm{nm}$. The lamp was used at a distance of $100 \mathrm{~mm}$ from the aqueous solution in a dark box. The initial concentration of $\mathrm{MB}$ was set at $1 \times 10^{-5} \mathrm{~mol} / \mathrm{L}$ in all experiments. The amount of the Y-fullerene $/ \mathrm{TiO}_{2}$ composite was $50 \mathrm{mg}$ per $50 \mathrm{ml}$. The reactor was placed for $2 \mathrm{~h}$ in a darkness box to let the Y-fullerene $/ \mathrm{TiO}_{2}$ composites particles adsorb $\mathrm{MB}$ molecules to equilibrium. After the adsorption, visible light irradiation was started to begin the degradation reaction. In the degradation of $\mathrm{MB}$, a glass reactor (diameter $4 \mathrm{~cm}$, height 6 $\mathrm{cm}$ ) was used and the reactor was placed on the magnetic churn dasher. The suspension was then irradiated with visible light for a set irradiation time. Visible light irradiation times of the reactor were $10,30,60,90$, and 120 min. Samples were withdrawn regularly from the reactor and dispersed powders were removed by a centrifuge. The clean transparent solution was analyzed by UV-Vis spectroscopy. The MB concentration in the solution was determined as a function of the irradiation time. The concentration of $\mathrm{MB}$ in the solution was then determined as a function of irradiation time from the change in absorbance at the wavelength of $660 \mathrm{~nm}$.

\section{Results and discussion}

\subsection{Phase structure and elemental analysis}

The XRD patterns of the $\mathrm{Y}$-fullerene/ $\mathrm{TiO}_{2}$ composites are shown in Fig. 1. The major peaks at $2 \theta$ values of 25.3, 37.9, $48.0,53.8,54.9$, and $62.5^{\circ}$ corresponded to diffractions of the (101), (004), (200), (105), (211), and (204) planes of anatase $\mathrm{TiO}_{2}$. This showed that the $\mathrm{TiO}_{2}$ prepared existed in

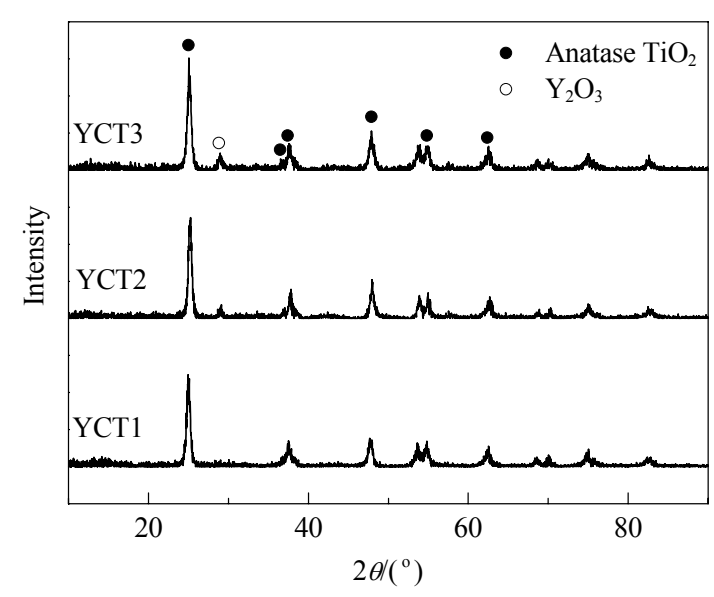

Fig. 1. XRD patterns of $\mathrm{Y}$-fullerene/ $/ \mathrm{TiO}_{2}$ composites. the anatase phase [27]. The results indicated that Y-fullerene $/ \mathrm{TiO}_{2}$ with different yttrium doping prepared under the current conditions all showed the pure anatase phase structure. In addition, a peak at $2 \theta=37.0^{\circ}$ corresponded to the diffraction of the (103) plane of anatase $\mathrm{TiO}_{2}$. With the increase of yttrium, this peak became increasingly more intense, showing that $\mathrm{Y}$-doping has an effect on the crystallization of $\mathrm{TiO}_{2}$. The results revealed that the incorporation of the dopant ions decreased the crystallite size. In the XRD patterns of the $\mathrm{Y}$-fullerene/ $/ \mathrm{TiO}_{2}$ samples, the formation of $\mathrm{Y}_{2} \mathrm{O}_{3}$ from the change of the rare earth salt into rare earth oxide during the calcination was sought. A peak at $2 \theta=29.2^{\circ}$ value indicates characteristic (222) diffraction of $\mathrm{Y}_{2} \mathrm{O}_{3}$ particles [28]. This was not clearly observed from YCT1, which was ascribed to the fact that the concentration of Y-doping was so low and the overlapping of diffraction peaks due to $\mathrm{TiO}_{2}, \mathrm{Y}_{2} \mathrm{O}_{3}$, and the CNT support.

Further data for the composition of the photocatalysts were obtained by EDX analysis (expressed as atomic percentage of cationic elements) measured all along fragments of fresh monoliths. The results are shown in Fig. 2 , and showed that the distributions of the elements were homogeneous. Figure 2 shows strong $K_{\alpha}$ and $K_{\beta}$ peaks from $\mathrm{Ti}$ at 4.51 and $4.92 \mathrm{keV}$, and a moderately strong $K_{\alpha}$ peak for $\mathrm{O}$ appeared at $0.52 \mathrm{keV}$ [23]. In addition, $\mathrm{Y}$ was also observed. The photocatalysts were composed of the

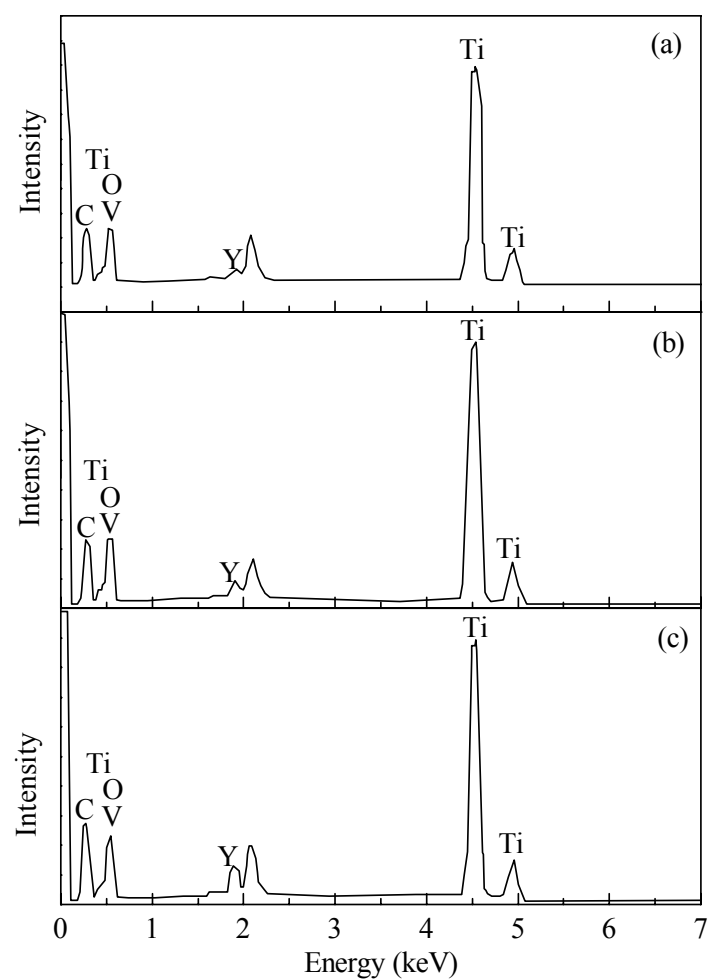

Fig. 2. EDX spectra of $\mathrm{Y}$-fullerene/ $\mathrm{TiO}_{2}$ composites. (a) $\mathrm{YCT} 1$; (b) YCT2; (c) YCT3. 
Table 1 EDX elemental microanalysis of $\mathrm{Y}$-fullerene/TiO composites

\begin{tabular}{lcccc}
\hline \multirow{2}{*}{ Sample } & \multicolumn{4}{c}{ Content (\%) } \\
\cline { 2 - 5 } & $\mathrm{C}$ & $\mathrm{O}$ & $\mathrm{Ti}$ & $\mathrm{Y}$ \\
\hline YCT1 & 12.01 & 53.06 & 33.73 & 1.20 \\
YCT2 & 12.97 & 53.88 & 30.64 & 2.51 \\
YCT3 & 14.77 & 49.10 & 32.08 & 4.05 \\
\hline
\end{tabular}

elements $\mathrm{Ti}, \mathrm{C}, \mathrm{O}$, and $\mathrm{Y}$. These results confirm that $\mathrm{C}$, $\mathrm{Ti}$, $\mathrm{O}$, and $\mathrm{Y}$ existed in the catalyst structure. The results of the EDX elemental microanalysis of the Y-fullerene/ $/ \mathrm{TiO}_{2}$ composites are listed in Table 1. The contents of the yttrium component for YCT1, YCT2, and YCT3 were 1.20\%, $2.51 \%$, and $4.05 \%$. It was expected that the contents of the yttrium component in the composites would increase with an increase of $\mathrm{Y}\left(\mathrm{NO}_{3}\right)_{3}$ concentration.

\subsection{Surface characteristics}

The BET surface areas of the $\mathrm{Y}$-fullerene/TiO composites are shown in Table 2. The BET surface area of non-yttrium treated fullerene $/ \mathrm{TiO}_{2}$ was $120 \mathrm{~m}^{2} / \mathrm{g}$, while the BET surface area of yttrium-treated fullerene $/ \mathrm{TiO}_{2}$ decreased from 47 to $27 \mathrm{~m}^{2} / \mathrm{g}$ with an increased of $\mathrm{Y}\left(\mathrm{NO}_{3}\right)_{3}$ concentration. The micro-surface structure and morphology of the Y-fullerene/ $\mathrm{TiO}_{2}$ composites were characterized by SEM and the results are shown in Fig. 3. It can be seen that
Table 2 Specific BET surface areas of the $\mathrm{Y}$-fullerene/ $/ \mathrm{TiO}_{2}$ composites

\begin{tabular}{lc}
\hline Sample & $A_{\mathrm{BET}} /\left(\mathrm{m}^{2} / \mathrm{g}\right)$ \\
\hline $\mathrm{C}_{60}$ & 85 \\
$\mathrm{C}_{60} / \mathrm{TiO}_{2}$ & 120 \\
$\mathrm{YCT} 1$ & 47 \\
$\mathrm{YCT} 2$ & 38 \\
$\mathrm{YCT} 3$ & 31.7 \\
\hline
\end{tabular}

the grains of the specimens with different recipes in the preparation were unlike, which means that the impurity phases influence the microstructure. From (a) to (c), the grain sizes of the samples were not uniform. Floccules $\left(\mathrm{Y}_{2} \mathrm{O}_{3}\right)$ can be found in the $\mathrm{Y}$-fullerene $/ \mathrm{TiO}_{2}$ composites and these increased with an increase of $\mathrm{Y}\left(\mathrm{NO}_{3}\right)_{3}$ concentration. The distribution of grains was very uniform and the grains were deposited close to each other. Zhang et al. [29] reported that a good dispersion of small particles provides more reactive sites for the reactants than aggregated particles. The conductivity of the fullerene facilitates electron transfer between adsorbed dye molecules and the catalyst substrate.

Figure 4 shows TEM images of Y-fullerene and $\mathrm{Y}$-fullerene $/ \mathrm{TiO}_{2}$ composites at different magnifications. The interfacial region of $\mathrm{Y}$-fullerene and $\mathrm{Y}$-fullerene/ $\mathrm{TiO}_{2}$ were examined by TEM to get more information on the interfacial region of the fullerene crystals and to identify the

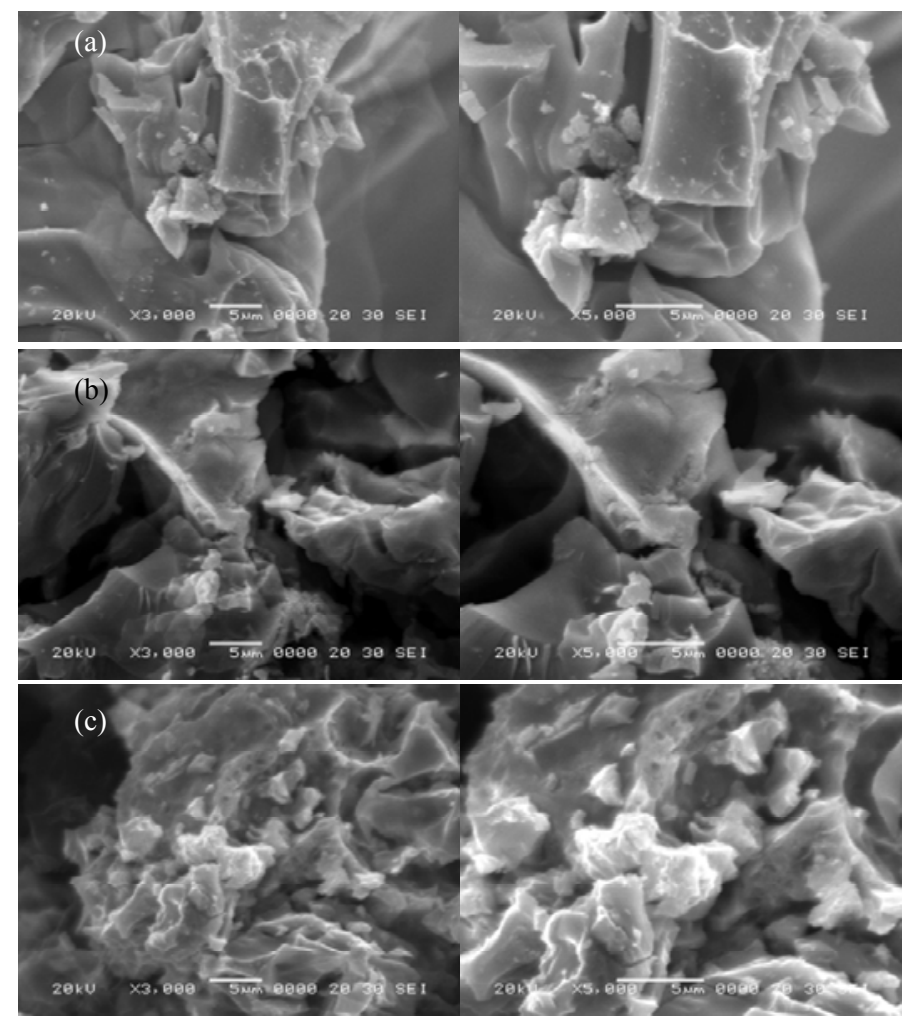

Fig. 3. SEM micrographs of Y-fullerene/TiO ${ }_{2}$ composites. (a) YCT1; (b) YCT2; (c) YCT3. 


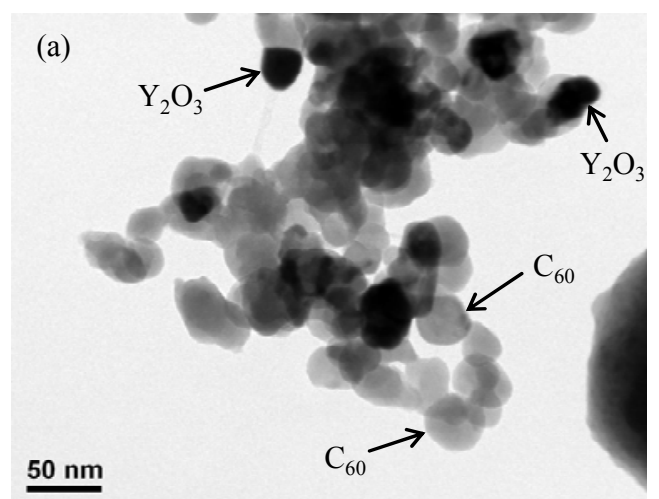

(b)

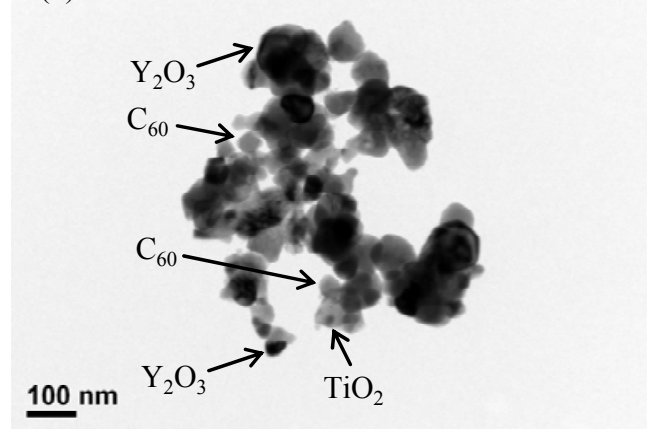

Fig. 4. TEM images of Y-fullerene (a) and $\mathrm{Y}$-fullerene/ $/ \mathrm{TiO}_{2}$ (b) composites.

potential reaction products in this domain. In Fig. 4, large clusters were observed with an irregular agglomerate dispersion of $\mathrm{TiO}_{2}$. The $\mathrm{C}_{60}$ particles are clearly shown in this picture. The light, spherical shape figures in Fig. 4 are $\mathrm{C}_{60}$. The average diameter of $\mathrm{C}_{60}$ was estimated to be $30 \mathrm{~nm}$. The TEM image in Fig. 4 showed that the powders prepared were uniform with some aggregations of particles. Yttrium oxide particles were also observed as black points in the TEM image.

\subsection{UV-Vis diffuse reflectance spectroscopy}

The UV-Vis absorption spectra of the samples are shown in Fig. 5. We can see $\mathrm{TiO}_{2}$, fullerene/ $/ \mathrm{TiO}_{2}, \mathrm{Y}-\mathrm{TiO}_{2}$, and Y-fullerene/ $/ \mathrm{TiO}_{2}$ composites have a large absorption in the ultraviolet region, but the absorption edge of $\mathrm{TiO}_{2}$ is approximately $400 \mathrm{~nm}\left(E_{\mathrm{g}}=3.2 \mathrm{eV}\right)$. $\mathrm{Y}_{-}-\mathrm{TiO}_{2}$ compounds have good absorption because $\mathrm{Y}_{2} \mathrm{O}_{3}$ retards charge-pair recombination and can trap electrons into the conduction band of $\mathrm{TiO}_{2}$. In the visible region, fullerene- $\mathrm{TiO}_{2}$ and Y-fullerene/ $\mathrm{TiO}_{2}$ composites have good absorption. This means these composites can have photocatalytic activity under visible light irradiation. In the case of fullerene-coupled $\mathrm{TiO}_{2}$, fullerene acts as a photosensitizer, which can be excited to inject electrons into the conduction band of $\mathrm{TiO}_{2}$. Y can retard charge-pair recombination and

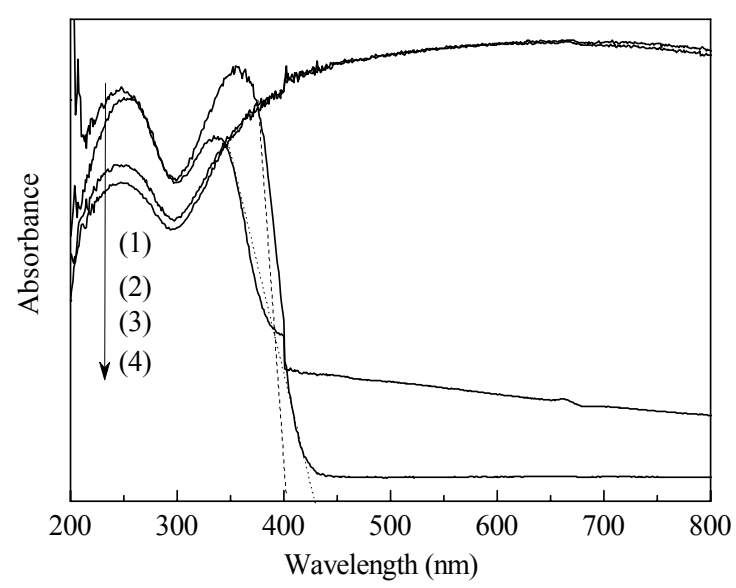

Fig. 5. UV-Vis absorption spectra of the photocatalysts. (1) $\mathrm{TiO}_{2}$; (2) Y-TiO 2 ; (3) Y-fullerene/ $\mathrm{TiO}_{2}$; (4) Fullerene/ $\mathrm{TiO}_{2}$.

trap electrons in the conduction band. Due to the synergistic reaction of $\mathrm{Y}$, fullerene, and $\mathrm{TiO}_{2}$, the absorption of $\mathrm{Y}$-fullerene/ $\mathrm{TiO}_{2}$ is good in the visible region.

\subsection{Decolorization of $\mathrm{MB}$}

Figure 6 shows the decolorization rate of $\mathrm{MB}$ over different Y-fullerene/ $\mathrm{TiO}_{2}$ composites under visible light irradiation. The decolorization of MB solution has two steps: one is adsorption of MB by the photocatalyst which is determined by the BET surface area [30], and the other is the photo-degradation of MB by the photocatalyst which is determined by the activity of the photocatalyst [31]. In order to distinguish difference between the visible light photocatalytic process and the dye induced photosensitized process, we compare the degradation effect between the cases of with photocatalyst and without photocatalyst. We found that with the presence of the photocatalyst, the degradation of the MB solution was good. From Fig. 6, we

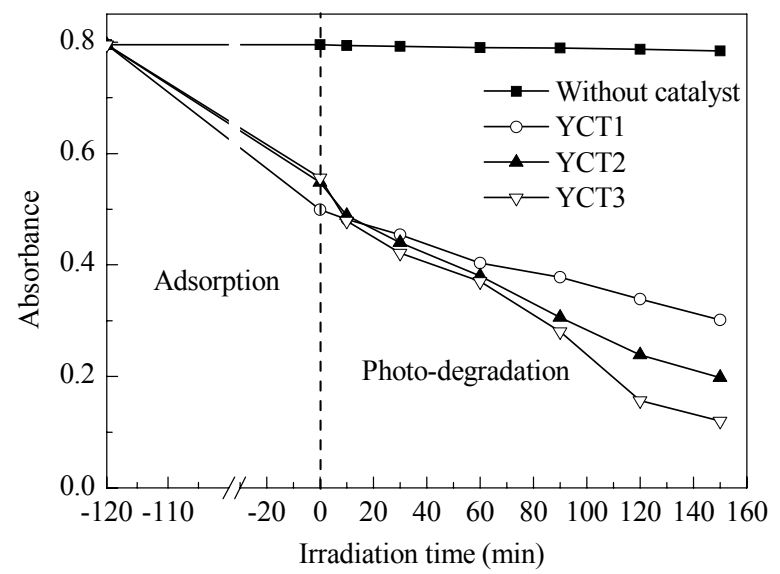

Fig. 6. Photocatalytic degradation of MB by different Y-fullerene/ $\mathrm{TiO}_{2}$ composites under visible light irradiation. 
can see that the adsorption capacity of YCT1 was better than the other two samples. Many MB molecules were adsorbed on the Y-fullerene/ $\mathrm{TiO}_{2}$ composites due to the large BET surface areas. During the photo-degradation step, the absorbance of the MB solution decreased rapidly. After $150 \mathrm{~min}$, the absorbance of MB solution was very small, and the color of the MB solution was light. The photo-degradation rate by the Y-fullerene/ $\mathrm{TiO}_{2}$ composite increased with an increase of yttrium concentration. The color of the MB solution degraded by YCT3 was very light and the absorbance value was low. YCT3 had the best photocatalytic activity.

\subsection{Kinetic studies}

For practical applications, the degradation kinetics of MB was investigated under mild conditions. The dependence of the photocatalytic degradation rate on the concentration of organic pollutants has been well described by the Langmuir-Hinshelwood mechanism. The modified Langmuir-Hinshelwood equation is given by:

$$
r=-k_{\mathrm{r}} \theta=k_{\mathrm{r}} K C /(1+K C)
$$

where $k_{\mathrm{r}}$ is the reaction rate constant, $K$ is the reactant adsorption constant, $\theta$ is the fraction of $\mathrm{TiO}_{2}$ surface coverage, and $C$ is the substrate concentration at time $t$.

When the substrate concentration was low enough (less than $10 \mathrm{mg} / \mathrm{L}$ in this study) and there was no catalyst saturation, $\mathrm{TiO}_{2}$ gives apparent first order kinetics. In this case, Eq. (1) can be simplified to an apparent first order kinetic model [32]:

$$
-\ln \left(C / C_{0}\right)=k_{\mathrm{r}} K t=k_{\mathrm{app}} t
$$

The plots of $-\ln \left(C / C_{0}\right)$ versus time in Fig. 7 gave straight lines. The slope gave the apparent first-order rate constant, $k_{\text {app. }}$. The MB solution was quite unstable when it was irradiated by visible light in the presence of Y-fullerene $/ \mathrm{TiO}_{2}$ composites. As mentioned above, fullerene is an energy sensitizer for improving the quantum efficiency

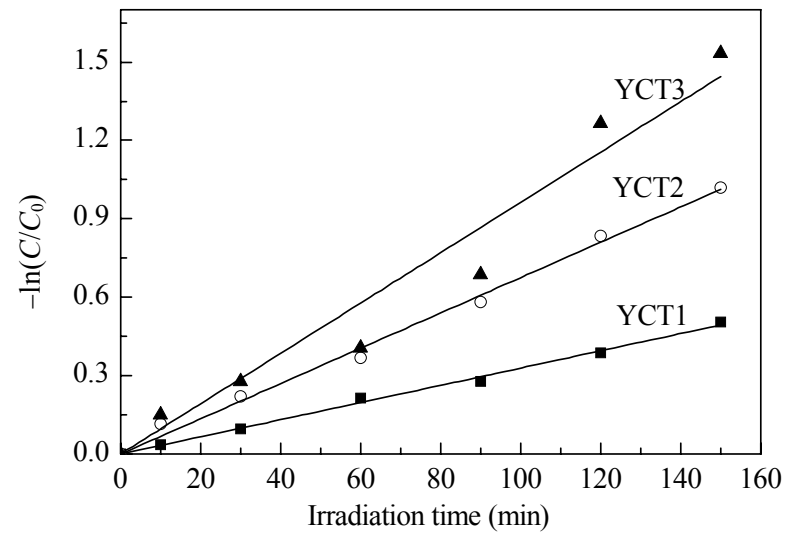

Fig. 7. Apparent first order kinetics of $-\ln \left(C / C_{0}\right)$ against time for $\mathrm{MB}$ degradation by $\mathrm{Y}$-fullerene/ $\mathrm{TiO}_{2}$ composites. and an increase of charge transfer. The surface coverage of titanium dioxide particles was very low $(<1 \%)$ and therefore few photo-generated electrons were scavenged by fullerene. Further increase in fullerene concentration led to larger surface coverage, and therefore the number of scavenged photo-generated electron also increased. This resulted in higher photocatalytic efficiency (lower recombination). Further increase in the ratio can lead to the complete monolayer coverage of the titanium dioxide surface exposed to light, resulting in fewer photo-generated electron-hole pairs [33].

In the fullerene coupled $\mathrm{TiO}_{2}$ system, the enhancement of the photocatalytic activities was due mainly to the high efficiency of charge separation induced by the synergetic effects of fullerene and $\mathrm{TiO}_{2}$. Figure 8 shows the photo-generated charge transition during irradiation. When fullerene was coupled with $\mathrm{TiO}_{2}$, hole and electron pairs were generated and separated at the interface of fullerene upon illumination by visible light. The conduction band in $\mathrm{TiO}_{2}$ was lower than the reduction potential of fullerene $[34,35]$. Therefore, the photogenerated electron can transfer easily from the conduction band of fullerene to $\mathrm{TiO}_{2}$ due to the interaction between $\mathrm{TiO}_{2}$ and fullerene [36]. The synergetic effect of fullerene and $\mathrm{TiO}_{2}$ promoted the separation efficiency of photo-generated electron-hole pairs, resulting in a high photocatalytic activity of the fullerene-hybridized $\mathrm{TiO}_{2}$ samples. In this case, fullerene improved the activity of $\mathrm{TiO}_{2}$ under visible light irradiation [37].

Yttrium oxide is used to inhibit electron-hole pair recombination. For this supported catalyst system, it has been suggested that charge pair separation was due to electron donation from the fullerene- $\mathrm{TiO}_{2}$ framework and the electron-accepting role possessed by $\mathrm{Y}^{3+}$ ions (electron-trap) [38].

Fullerene- $\mathrm{TiO}_{2}+$ visible light $\rightarrow \mathrm{e}^{-}+\mathrm{h}^{+}$

$\mathrm{Y}^{3+}+\mathrm{e}^{-}+\mathrm{h}^{+}+\mathrm{H}_{2} \mathrm{O} \rightarrow \mathrm{Y}^{2+}+\mathrm{Y}^{4+}+\mathrm{O}_{2}^{-}+\mathrm{H}_{2}$ (electron-trap and hole-trap)

Another possible pathway with fullerene- $\mathrm{TiO}_{2}$ was an electron-delocalizing region. This route is relatively rare compared to the electron-donating route of the fullerene- $\mathrm{TiO}_{2}$ system due to the limited number of $\mathrm{C}_{60}$ sites in its structure. In both routes, the unstable nature of $\mathrm{Y}^{2+}$ and $\mathrm{Y}^{4+}$ ions initiates the transfer of trapped charges to the interface by the following equations.

$$
\mathrm{Y}^{2+}+\mathrm{O}_{2}+\mathrm{Y}^{4+}+\mathrm{OH}^{-} \rightarrow 2 \mathrm{Y}^{3+}+\mathrm{O}_{2}{ }^{--}+\mathrm{OH}^{-}
$$

Highly reactive superoxide ions $\left(\mathrm{O}_{2}{ }^{-}\right)$may also form hydroxyl radicals in acidic media. Oxidative degradation of azo dyes generally occurs by the attack by hydroxyl radicals, which are known highly reactive electrophilic oxidants $[39,40]$.

The values corresponding to different initial 


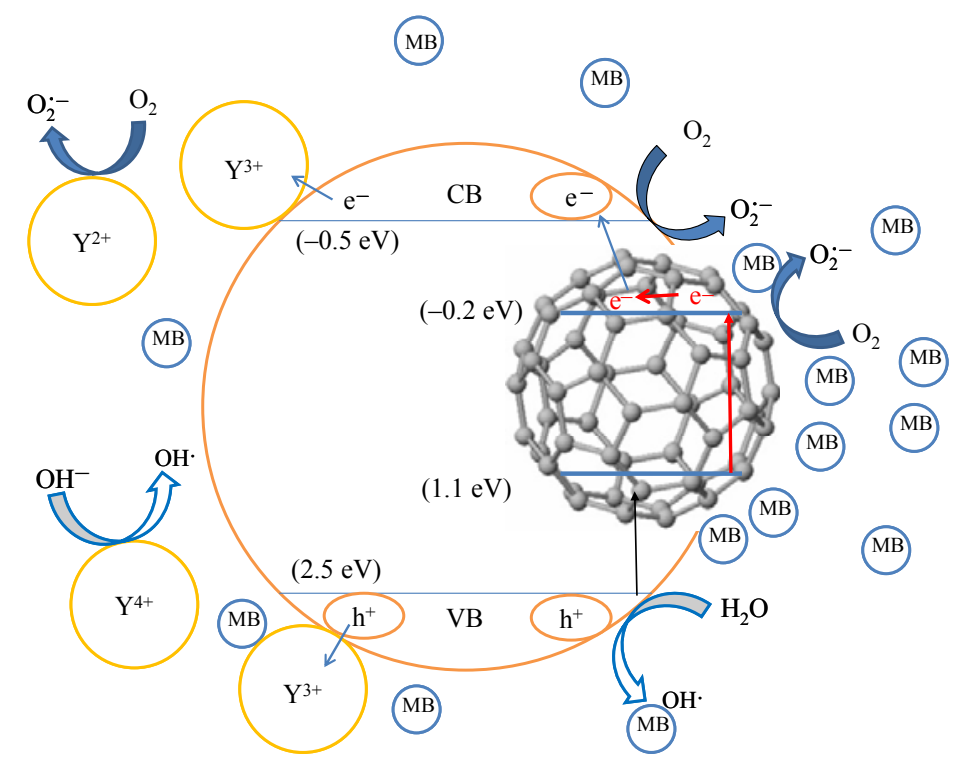

Fig. 8. Schematic of the separation of photo-generated electrons and holes at the $\mathrm{Y}$-fullerene/ $\mathrm{TiO}_{2}$ interface.

concentrations, along with the regression coefficients, are listed in Table 1. YCT1, YCT2, and YCT3 give apparent rate constants of $3.29 \times 10^{-3}, 6.75 \times 10^{-3}$, and $9.63 \times 10^{-3}$, respectively. For the Y-fullerene $/ \mathrm{TiO}_{2}$ composite, the $k_{\text {app }}$ values were $3.29 \times 10^{-3}-9.63 \times 10^{-3}$. It was evident that the photocatalytic activities of the Y-fullerene $/ \mathrm{TiO}_{2}$ composites were increased with an increase of yttrium concentration.

\section{Conclusions}

$\mathrm{Y}$-fullerene/ $\mathrm{TiO}_{2}$ composites were studied and composites with different yttrium contents were characterized by their structure, surface state, and photocatalytic activity. The XRD patterns of the Y-fullerene/ $/ \mathrm{TiO}_{2}$ composites showed peaks of high crystallinity anatase. In the SEM image, yttrium particles were regularly dispersed on the surface. The EDX spectrum showed the presence of $\mathrm{C}, \mathrm{O}$, and $\mathrm{Ti}$ as major elements, and showed strong $\mathrm{Y}$ peaks. TEM showed that $\mathrm{TiO}_{2}$ particles and some agglomerates were dispersed on the surface of fullerene together with Pt particles. UV-Vis results showed that fullerene $/ \mathrm{TiO}_{2}$ and $\mathrm{Y}$-fullerene $/ \mathrm{TiO}_{2}$ have good activity in the visible range. In the photo-degradation, the better decrease in $\mathrm{MB}$ concentration can be ascribed to the three effects of the photocatalytic reaction of the supported $\mathrm{TiO}_{2}$, decomposition of the organometallic reaction by the $\mathrm{Y}$ compound, and energy transfer effects of electrons and light of the fullerene.

\section{References}

1 Zhang F J, Chen M L, Zhang K, Oh W C. Bull Korean Chem Soc, 2010, 31: 133
2 Oh W C. J Photocatal Sci, 2010, 1: 29

3 Meng Z D, Zhang K, Oh W C. J Korean Cry Grow Cry Technol, 2009, 19: 268

4 Yang Y, Li X J, Chen J J, Wang L Y. J Photochem Photobiol A, 2004, 163: 517

5 Wu L, Yu J C, Wang X C, Zhang L Z, Yu J G. J Solid State Chem, 2005, 178: 321

6 Saquib M, Muneer M. Desalination, 2003, 155: 255

7 Xiang Q J, Yu J G, Jaroniec M. J Phys Chem C, 2011, 115: 7355

8 Yu J G, Ma T T, Liu S W. Phys Chem Chem Phys, 2011, 13: 3491

9 Kroto H W, Heath J R, O'Brien S C, Curl R F, Smaller R E. Nature, 1985, 318: 162

10 Sun Y P, Gudure R, Lawson G E, Mullins J E, Guo Z X, Quinlan J, Bunker C E, Gord J R. J Phys Chem B, 2000,104: 4625

11 Balch A L, Olmstead M M. Chem Rev, 1998, 98: 2123

12 Márquez F, Sabater M J. J Phys Chem A, 2005, 109: 1559

13 Nishimura T, Takatano K, Sakurai S, Maeda K, Yashima E. Angew Chem, Int Ed, 2002, 41: 3602

14 Segura J L, Martin N. Angew Chem, Int Ed, 2001, 40: 1372

15 Hasobe T, Imahora H, Kamat P V, Fukuzumi S. J Am Chem Soc, 2003, 125: 14962

16 Jehoulet C, Obeng Y S, Kim Y T, Zhou F M, Bard A J. J Am Chem Soc, 1992, 114: 4237

17 Shinohara H. Rep Prog Phys, 2000, 63: 843

18 Suzuki T, Kikuchi K, Oguri F, Nakao Y, Suzuki S, Achiba Y, Yamamoto K, Funasaka H, Takahashi T. Tetrahedron, 1996, 52: 4973

19 Okazaki T, Lian Y F, Gu Z N, Suenaga K, Shinohara H. Chem Phys Lett, 2000, 320: 435

20 Okazaki T, Suenaga K, Lian Y F, Gu Z N, Shinohara H. $J$ Chem Phys, 2000, 113: 9593

21 Yu G, Gao J, Hummelen J C, Wudl F, Heeger A J. Science, 
1995, 270: 1789

22 Li F B, Li X Z, Hou M F. Appl Catal B, 2004, 48: 185

23 Yuan S, Sheng Q R, Zhang J L, Chen F, Anpo M, Zhang Q H. Microporous Mesoporous Mater, 2005, 79: 93

24 Yan X L, He J, Evans D G, Duan X, Zhu Y X. Appl Catal B, 2005, 55: 243

25 Zhang Y H, Zhang H X, Xu Y X, Wang Y G. J Mater Chem, 2003, 13: 2261

26 Saif M, Abdel-Mottaleb M S A. Inorg Chim Acta, 2007, 360: 2863

27 Bhattacharyya A, Kawi S, Ray M B. Catal Today, 2004, 98: 431

28 Anandan S, Yoon M. J Photochem Photobiol C, 2003, 4: 5

29 Zhang X W, Zhou M H, Lei L C. Carbon, 2005, 43: 1700

30 Zhang F J, Chen M L, Oh W C. J Korean Ceram Soc, 2009, 46: 554

31 Zhu L, Meng Z D, Chen M L, Zhang F J, Choi J G, Park J Y,
Oh W C. J Photocatal Sci, 2010, 1: 69

32 Oh W C, Zhang F J, Chen M L. J Ind Eng Chem, 2010, 16: 299

33 Chae S R, Watanabe Y, Wiesner M R. Water Res, 2011, 45: 308

34 Shiga T, Motohiro T. Thin Solid Films, 2008, 516: 1204

35 Canesi L, Fabbri R, Gallo G, Vallotto D, Marcomini A, Pojana G. Aquat Toxicol, 2010, 100: 168

36 Makarov V I, Kochubei S A, Khmelinskii I V. Chem Phys Lett, 2002, 355: 504

37 Moriarty P J. Surf Sci Reports, 2010, 65: 175

38 Yu J G, Ma T T, Liu G, Cheng B. Dalton Trans, 2011, DOI: 10.1039/C1DT10274E

39 Stylidi M, Kondarides D I, Verykios X E. Appl Catal B, 2004, 47: 189

40 Zhang Q T, Li B, Li H L, Zhang X P. J Rare Earth, 2007, 25: 30 